\title{
El lado oscuro de la maternidad: actualización de mitos en la película The Extraordinary Tale of the Times Table (2013)
}

\section{Resumen}

El cine a menudo bebe de historias ancestrales para llegar al corazón del público. Estas historias se componen de una serie de elementos configuradores esenciales del imaginario colectivo de las culturas a lo largo de la historia, que varían paralelamente a los cambios sociales.

El objetivo principal de este estudio se centra en analizar cómo la película The Extraordinary Tale of the Times Table (2013), de José Francisco Ortuño y Laura Alvea reconstruye una invariante específica: el desprecio de la figura paterna/materna hacia el hijo, que se ha plasmado en numerosas ocasiones a través del mito de Tántalo, Saturno devorando a sus hijos, Hera o Medea, entre otros. En el audiovisual, el mito se estudiará canalizado a través de dos aspectos: por un lado, la utilización de elementos compositivos concretos (color, líneas, texturas, distribución de elementos en el cuadro), y por otro, se analiza el sentido profundo del texto para desentrañar la arquitectura del mito en el audiovisual a través de un estudio de caso.

Referencias básicas de este análisis son los planteamientos metodológicos de Erwin Panofsky y Roland Barthes que ayudarán a ver de qué manera las preocupaciones existenciales del ser humano encuentran en el arte, en este caso el cine, un canal idóneo para actualizarse y adaptarse a la contemporaneidad.

\author{
Ángeles Martínez-García \\ Doctorado en Comunicación, PhD \\ Profesora Universidad de Sevilla, \\ España \\ Correo electrónico: \\ angelesmartinez@us.es \\ ๑ orcid.org/0000-0002-9102-9583 \\ Google Scholar
}

\begin{abstract}
Antonio Gómez-Aguilar Doctorado en Comunicación, PhD Profesor Universidad de Sevilla, España

Correo electrónico: agomez16@us.es (- orcid.org/0000-0003-2819-3441 Google Scholar
\end{abstract}

Recibido: Abril 7 de 2018 Aprobado: Mayo 06 de 2019

Palabras clave:

Cine, iconología, maternidad, mito, símbolo. 


\title{
The dark side of maternity: updating of myths in the film The extraordinary tale of the times table (2013)
}

\begin{abstract}
The cinema often feeds from ancestral stories to really hit home. These stories are made up of essential configurating elements of the collective imaginary of cultures throughout history and change at the same time as social changes.

The main objective of this study is to analyze how the film The Extraordinary Tale of the Times Table (2013) by José Francisco Ortuño and Laura Alvea reconstructs a specific constant: the contempt of the paternal / maternal figure towards the son, which has been expressed many times through the myth of Tantalus, Saturn devouring his children, Hera and Medea, among others. Myths in the audiovisual will be studied channeled through two aspects: on the one hand, the use of specific compositional elements (colour, lines, textures, distribution of elements inside the shot) and on the other hand, the deeper meaning is analyzed to unravel the architecture of the myth in the audiovisual through a case study.

Basic references of this article are the methodological approaches by Erwin Panofsky and Roland Barthes that will help to find out in what way the existential concerns of the human being find in the art, in this case the cinema, an appropriate channel to update and adapt to contemporaneity.
\end{abstract}

Key words:

Cinema, iconology, motherhood, myth, symbol. 
En la difícil tarea de definir los mitos, Robert A. Segal (2004) apunta hacia un aspecto que tiene que ver con su esencia más primigenia: todo mito es una historia, un relato. En sus orígenes, el mito nace con la intención de explicar cuestiones inherentes a la naturaleza humana y a su entorno, esto es, como la primera forma de relación del ser humano con lo que le rodea (Huici, 1998). Esa función primera entronca con otra, la de la búsqueda de sentido en tanto que resuelve lo indecible de un dilema (Durand, 2013). Además, el mito traza las constantes existenciales de la humanidad, sus signos de identidad o su sistema de referencia último (Kolakowski, 1990). Estos relatos a menudo están protagonizados por seres de naturaleza sobrenatural -dioses y héroes emparentados con ellos- y fijan una serie de modelos ejemplares de acciones humanas significativas (Rosales, 1996). Desde esta consideración los mitos aparecen como realidades complejas (Eliade, 1999) cuyas posibilidades de investigación son muy variadas, en tanto que son un producto colectivo (Cencillo, 1998) y tienen su origen no ya en la lógica y el razonamiento, sino en la parte intuitiva del ser humano.

Tal y como apuntan Jung y Kerényi (2004):

la mitología: es la suma de elementos antiguos transmitidos por la tradición (...), que tratan de los dioses y los seres divinos, combates de héroes y descensos a los infiernos, elementos contenidos en relatos conocidos y que, sin embargo, no excluyen la continuación de otra creación más avanzada. La mitología es el movimiento de esta materia: algo firme y móvil al mismo tiempo, material pero no estático, sujeto a transformaciones. (p. 17)

Esta idea entronca con la tesis que subyace a la obra De la mitocrítica al mitoanálisis (2013) de Gilbert Durand de que no existe interrupción alguna entre los argumentos significativos de las antiguas mitologías y los relatos modernos. Las sociedades arcaicas se definían por su carácter cíclico, algo que fue superado posteriormente por una concepción de la historia lineal e irreversible. Este paso crucial en la historia del ser humano viene marcado por 
la aparición de la escritura, que propiciará más adelante la aparición de la filosofía y con ello una profunda crisis del mito. Tal y como apunta Marshall McLuhan (1985, p. 28) "la interiorización de la tecnología del alfabeto fonético traslada al hombre desde el mundo mágico del oído al mundo neutro de lo visual". Este argumento coincide con los estudios de Eric A. Havelock (1996) que apunta que "la revolución alfabética se da con la creación de un tema como sujeto de un discurso" (p. 140) lo que posibilita usar la lógica en lugar de la narración. Precisamente durante el periodo de la transmisión oral era la concatenación de acciones que ejemplificaran un razonamiento -mecanismo de funcionamiento de los mitos- la manera de funcionar. Sin embargo, con la Ilegada de la escritura se alcanza un nivel de abstracción superior trabajando las conexiones lógicas. Es esto lo que pone en jaque a los mitos fundacionales y da paso al nacimiento de la filosofía como disciplina que permite al ser humano reflexionar sobre sí mismo. El nacimiento de la escritura como punto de inflexión que marca "la fijación de la memoria colectiva" (García Gual, 1989, p. 31) supone un cambio crucial para que el mito se convierta en lo que es hoy en día (Duch, 2002). A partir de ese momento surge una dicotomía mythos-logos, que da origen a un confrontamiento entre una consciencia mítica, dionisíaca, y una consciencia racional o apolínea. El mito pasa a ser cuestionado y se apuesta por la búsqueda de una explicación del mundo apoyada en una investigación de carácter lógico y racional. Aunque aparentemente el logos tuviese más opciones de salir victorioso, no fue así: el cientificismo no es omnipotente frente a todos los dilemas del universo. Ya decía Platón que el mito es un modo de expresar aquellas verdades a las que escapa la razón y precisamente es la Edad Media una época caracterizada por prestar mucha atención a los mitos y a su poder explicativo.

Esta dicotomía mythos-logos se reaviva durante el Renacimiento con un debate que, si bien había permanecido latente, nunca había sido considerado con la fuerza de este momento: la verdad, el problema de la realidad de los mitos 
(Ferrater Mora, 1992). La separación definitiva entre mythos y logos se produce definitivamente en los siglos XVII y XVIII. Se ensalza el proceder de la ciencia, de carácter reduccionista, en detrimento de la intuición y, aparentemente, lo cuantitativo vence la batalla frente a lo cualitativo; es el triunfo de la razón, del dominio del ser humano sobre su entorno. El siglo XIX sigue en esta línea (Eliade, 1999), y no es hasta el siglo XX cuando los investigadores empiezan a integrar aspectos cualitativos además de cuantitativos en los planteamientos científicos (Lévi-Strauss, 1987). Esto es lo que Carlos García Gual (1989, p. 46-50) ha denominado "rehabilitación del mito", que se produce gracias a la lección alegórica, esto es, su funcionamiento metafórico. Se presenta como un lenguaje cifrado que aporta mucho más en un nivel oculto.

El individuo contemporáneo ha comprendido que es incapaz de aprehender todo a su alrededor y que debe seguir buscando referencias a las que asirse para llenar su vacío existencial. De este modo, además de la referencia a mitos ancestrales, sigue creando figuras clave en el seno de las distintas esferas sociales, como el cine, la literatura, las artes, en definitiva, y también otros ámbitos, como el deporte o los videojuegos.

La composición de los mitos se relaciona de forma muy estrecha con su capacidad de supervivencia: están formados por una serie de invariantes que han sido consideradas desde diversos puntos de vista. Por ejemplo, la corriente estructuralista encabezada por Claude Lévi-Strauss deja al margen la escuela simbolista; y la escuela funcionalista, que se preocupa únicamente del contexto social de los mitos y su papel en la sociedad. En su lugar, se centra en un análisis exhaustivo de la estructura interna de los mitos para desentrañar el sentido. Considera que las unidades mínimas significativas de los mitos son los mitemas, de una forma similar a los fonemas que existen en fonética. Lévi-Strauss (1958) dice que estas "unidades constitutivas mayores" actúan en el plano del lenguaje y diseña una metodología que parte de cada mito 
tomado de forma individual para segmentar la sucesión de acontecimientos y posteriormente reagruparlos con base en rasgos comunes.

De forma coetánea a Lévi-Strauss, surge un grupo de investigadores que pretende alejarse de la visión estructuralista que considera los mitos desde un punto de vista sincrónico. Ellos critican que el mito quede reducido a estructuras lingüísticas y apuestan por un acercamiento a través de la imagen, que es la que verdaderamente se aproxima a la naturaleza del mito. Surge en esta corriente el concepto de mitologema como unidad mínima de significado del mito, más cercano al análisis simbólico. En lugar de una unidad narrativa, se trata de una unidad icónica e imaginativa y es un tema que tiene cierta entidad propia y que puede replicarse en otras mitologías. El término es acuñado por Jung y Kerényi (2004), que lo entienden como un complejo de material mítico que es continuamente revisado, plasmado y reorganizado. Es la unidad primaria de significación de los mitos y se acerca mucho al concepto de arquetipo de Gustav Jung (1968), que se completa con elementos culturales y da origen al mito.

Los mitologemas han sido el origen tanto de la religión como de los sueños, los mitos o los cuentos de hadas, en tanto que todos ellos beben de los mismos temas globales. También de las leyendas urbanas, las películas y los videojuegos. Evolucionan, pero siempre lo hacen de forma más lenta que las representaciones a través de las cuales se manifiestan y habitualmente responden a un cambio social profundo (Stefanello, 2008).

Para esta investigación se partirá de que las invariantes de los mitos se caracterizan por aunar ambos planteamientos: tienen una naturaleza narrativa e icónica al mismo tiempo.

Este artículo se centra en una hipótesis concreta: las invariantes de los mitos se actualizan a lo largo de la historia, fundamentalmente, porque apelan a las 
preocupaciones esenciales del ser humano desde el principio de los tiempos. Para ello se valen de múltiples canales, aunque tal vez el arte sea el más fructífero de todos por su maleabilidad, y el cine es un ejemplo paradigmático. En este texto se estudia cómo la película The Extraordinary Tale of the Times Table (2013) revisa un tema "culturalmente" incorrecto: la maternidad desde un punto de vista negativo, basándose en dos puntales. Por un lado, relatos míticos que son la base del imaginario colectivo occidental, tales como aquellos que recogen la figura de Medea, Hera, entre otros. Por otro lado, una estética visual muy particular que hace posible la catarsis del espectador. Ambos construirán un nuevo edificio, la película, que actualiza y reinventa relatos ancestrales.

Los principales objetivos de este artículo son:

- Identificar los temas fundamentales que permiten hablar de actualización de mitos en la obra cinematográfica seleccionada.

- Analizar cuál es la información acerca de aspectos culturales que ofrece un producto audiovisual sobre el contexto en que se produce y recibe.

- Analizar los códigos visuales y el aparato temático e imbricar ambos con la dimensión simbólica del filme para desentrañar el significado latente de la película.

\section{Metodología}

\section{Estrategias metodológicas}

Para el desarrollo de la investigación se ha elegido un método cualitativo basado en la iconografía/iconología y al que se unirán elementos del método semiológico en el análisis de los mitos, considerados estos como sistema semiológico segundo (Barthes, 1999). El modelo iconográfico de Erwin Panofsky (1987) es heredero de 
los planteamientos de Aby Warburg (2010), que plantea la iconología como un método analítico del contenido visual (Müller, 2010) que estudia la interacción entre forma y contenido y añade la interdisciplinariedad al estudio del arte, que es el punto de partida de esta investigación. Erwin Panofsky está fuertemente influenciado por las ideas de Ernst Cassirer referentes a la búsqueda de los valores simbólicos o de Siegfried Kracauer, que amplía la iconología al campo de las imágenes en movimiento. En 1939, Erwin Panofsky establece tres niveles de significación en la obra de arte:

- Preiconográfico: reconocimiento de objetos a simple vista.

- Iconográfico: reconocimiento de tramas y subtramas del relato de la obra.

- Iconológico: fin último al que aspira el análisis. Reconocimiento del contenido simbólico de una obra, el significado profundo.

A pesar de sus limitaciones, el legado de la iconología es evidente ya que puede considerarse "as a critical, analytical, and transdisciplinary method with a bifocal perspective - focusing on the visual aspects of contemporary problems in politics, society, and culture, reflected in the lens of through historical comparison"1 (Müller, 2011, p. 285).

A partir de estos planteamientos, Ernst Gombrich (1986) conjuga posteriormente iconología y psicoanálisis, ya que apunta que la interpretación de los símbolos en la obra de arte es el enlace que une ambas disciplinas. Él comenta que además del simbolismo socialmente aceptado, debe tenerse en cuenta el simbolismo personal del artista. Añade que la iconología debe tener en cuenta los aspectos formales en cuanto a significado y concede una importancia extraordinaria a la experiencia y los condicionantes culturales. Siguiendo estos planteamientos, Ernst Cassirer (1998) ahonda en la condición simbólica del

\footnotetext{
1 "Como un método crítico, analítico y transdisciplinario con una perspectiva bifocal -focalizando en los aspectos visuales de los problemas contemporáneos en el ámbito político, social y cultural, reflejados en la lente de la comparación histórica” [Traducción propia].
} 
ser humano, que crea símbolos en todas las épocas y en todos los ámbitos y, por tanto, la visión del mundo depende de los valores culturales, conformada aquella fundamentalmente por el universo de símbolos que se manejan. El arte no es representativo ni expresivo, sino simbólico. De esta forma, sirve para aprehender la realidad y comunicar algo respecto a ella de manera indirecta.

Interesa para esta investigación la aportación de Theo van Leeuwen (2001), que conecta el planteamiento de Erwin Panofsky con la semiótica de Roland Barthes, en un intento por encontrar similitudes y diferencias entre ambos:

These two approaches ask the same two fundamental questions: the question of representation (what do images represent and how?) and the question of the "hidden meanings" of images (what ideas and values do the people, places and things represented on images stand for?). ${ }^{2}$ (p. 92)

Mientras que la semiótica visual de Barthes se centra fundamentalmente en la imagen y los sentidos culturales que activa, la iconografía - iconología presta mayor atención al contexto en que la imagen se produce y se distribuye, por lo que el sentido aparece imbricado a la historia de forma mucho más contundente.

Erwin Panofsky era reticente a aplicar su metodología al análisis fílmico ${ }^{3}$ y la relación entre la representación visual y la realidad no era muy relevante para él. Ponía el acento en el sentido más que en el realismo y la verdad (Walker \& Chaplin, 1997). Precisamente la metodología escogida para este trabajo partirá de sus presupuestos, añadiendo una dimensión simbólica más profunda al modo de Gombrich o Cassirer y tomando en consideración la idea de Theo van Leeuwen, que une los planteamientos iconográficos a la semiótica de Barthes.

\footnotetext{
2 "Estos dos acercamientos se plantean las mismas dos cuestiones fundamentales: la cuestión de la representación (¿qué representan las imágenes y cómo?) y la cuestión de los <significados ocultos> de las imágenes (¿qué ideas y valores conllevan las personas, lugares y cosas representadas?" [Traducción propia]

${ }^{3}$ El texto "Style and Medium in the Motion Pictures" (1936) recogido en el volumen Three Essays on Style es una de sus más importantes incursiones en el mundo del cine, aunque se centra más en la naturaleza de los filmes, quedando así enmarcado en la corriente ontológica de estudiosos como A. Bazin.
} 
De esta forma se da una dimensión más profunda a los planteamientos de Panofsky. Siguiendo a García (2017), se establecen tres fases en el análisis:

- Fase I: Enumeración de los componentes del lenguaje cinematográfico, es decir, identificar los elementos que aparecen en pantalla y cómo interaccionan estos en el universo diegético de la película.

- Fase II: Reconocimiento de los temas convencionales que aparecen en el filme. Hay que recurrir a fuentes y códigos cinematográficos o no. La mitología es una de las grandes fuentes de las que bebe la representación visual occidental, por ejemplo. En este punto, Roland Barthes servirá para desentrañar los temas invariantes (mitemas/mitologemas) presentes en el filme.

- Fase III: Identificación de los valores simbólicos, es decir, saber cómo interaccionan los elementos de los dos niveles anteriores para que aparezca el significado latente o profundo del filme en cuestión. Este sentido puede haber sido introducido de manera consciente por el creador de la película o puede hallarse de forma inconsciente, como síntoma de una época o lugar. Este último paso debe responder a la pregunta: "What information do the studied visuals convey about the social, political, and cultural context in which they were produced and perceived?"4 (Müller, 2011, p. 294).

\section{Objeto de estudio}

La película seleccionada es The Extraordinary Tale of the Times Table (2013), dirigida por José Francisco Ortuño y Laura Alvea y de nacionalidad española. La película está protagonizada por una chica que sufre un tipo de trastorno psicótico dentro del DSM IV ${ }^{5}$. Marcada por una infancia difícil y una madre que la trata de forma dictatorial, para posteriormente morir y dejarla sola y

\footnotetext{
4 “QQué información aportan los elementos visuales sobre el contexto social, político y cultural donde se produjeron y recibieron?" [Traducción propia].

${ }^{5}$ Criterios diagnósticos de los trastornos mentales.
} 
aislada del mundo exterior; siempre está en un estado de inseguridad, miedo e infantilismo extremos.

This is a lively, radiant young woman too, entirely innocent of the world, fragile and damaged by her relationship with her mother, who rather than tell her fairy stories as a child recited times tables to her -hence the title, and the resulting psychological damage. ${ }^{6}$ (Holland, 2013)

Ella cuenta en algún momento del metraje que sufre una enfermedad desde pequeña Ilamada anhedonia, que se traduce en la incapacidad para experimentar placer y, por tanto, la imposibilidad para ser feliz.

La chica, sin nombre identificativo en toda la película, al igual que Él, vive una existencia aislada en una casa peculiar. Ella ha escrito y enviado 1.212 cartas en 1.212 días sin respuesta, hasta que un día recibe una de alguien afín a ella. Tras mantener correspondencia por un tiempo deciden conocerse en persona. Esta idea le genera a Ella un estado de pánico. Su reacción es seguir comunicándose por escrito y la intermediación de la máquina de escribir se convierte en el mejor medio de comunicación, aparte del sexo. Empiezan a vivir juntos y ella se queda embarazada. Ahora, esta mujer que vive en una eterna infancia debe enfrentarse al mayor desafío de todos: ser madre.

Igualmente, el protagonista masculino también sufre algún tipo de trastorno marcado por una progenitora muy presente y de carácter fuerte, que acaba siempre machacando su personalidad. Tras el embarazo, Él consigue un trabajo; y el estado "ideal" en que estaban, acaba, y la convivencia se vuelve muy sombría y tediosa.

El resultado de la historia de esta extraña pareja es una comedia negra sobre el amor, el matrimonio, la maternidad y la muerte. Ambientada en un mundo 
donde no se aplican las reglas convencionales, la historia se convierte en una sátira cómica sobre las relaciones contemporáneas.

\section{Análisis de The Extraordinary Tale of the Times Table (2013)}

\section{Fase I: El lenguaje audiovisual (Nivel de significación primaria)}

\section{La composición visual}

Según Zavala (2009), "en la producción de un filme, el departamento de arte manipula lo visible para construir los espacios y ambientes de la realidad cinematográfica" (p. 19). El resultado en este caso es "un cuento de hadas oscuro" con cierto tono de irrealidad.

El primer elemento morfológico que destaca es el color. Tiene una función más utilitaria que plástica: debe propiciar las emociones contenidas en la historia que se cuenta (Figura 1). En The Extraordinary Tale of the Times Table los colores están asociados con los estados de ánimo de los personajes, sobre todo de la chica. Aparecen siempre difuminados, texturizados y en tonos pastel. Los momentos de máxima soledad de Ella aparecen en tonos más fríos, azules y verdes $(00: 40: 32)^{7}$; como cuando Él duerme mientras ella rompe aguas (00:41:56).

\footnotetext{
Se presentará con el formato (00:00:00) las horas, minutos y segundos del metraje de la película donde puede encontrarse una muestra de lo expuesto en el texto inmediatamente anterior.
} 

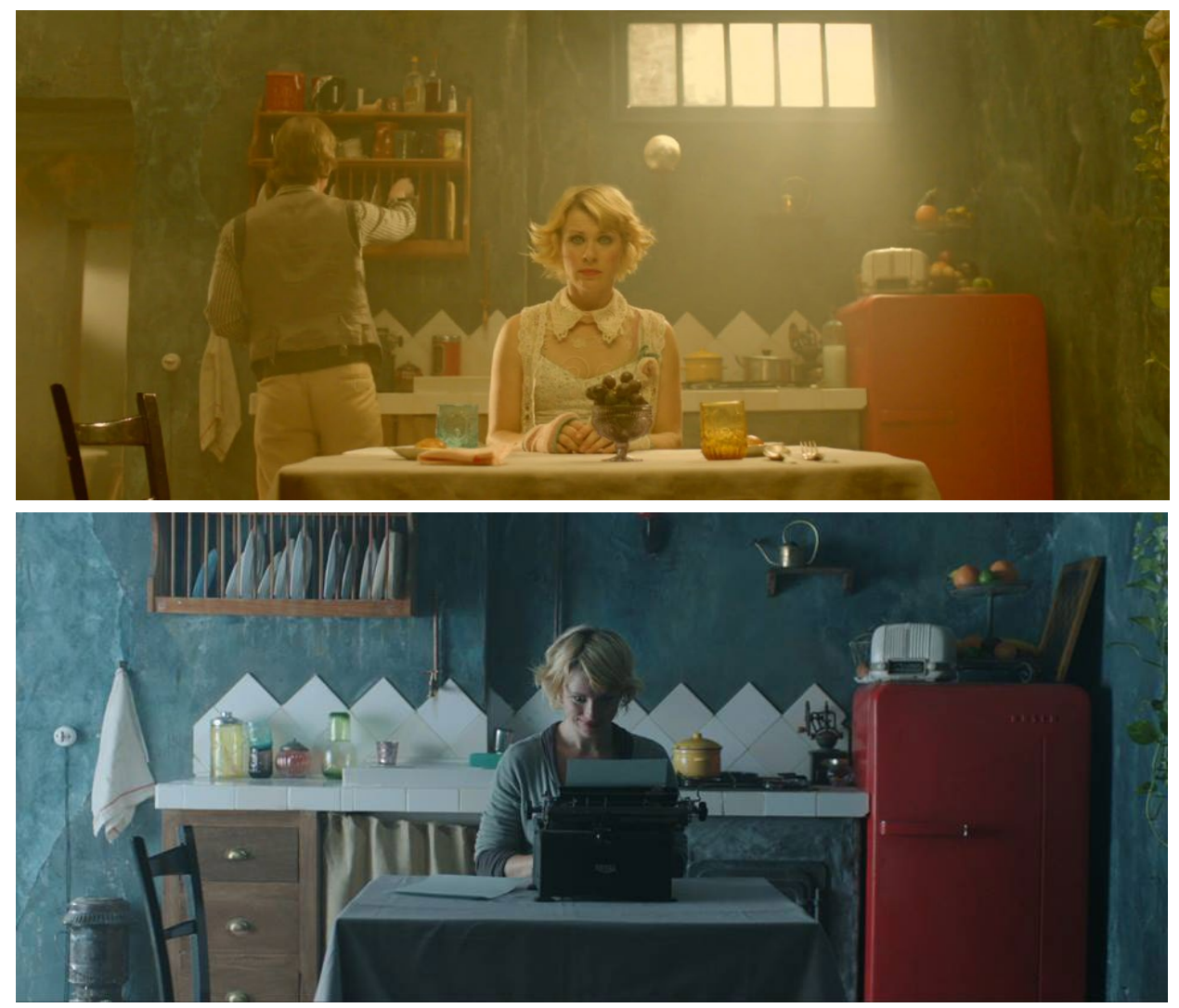

Figura 1. Comparativa en el uso del color en la película. La imagen superior corresponde a la primera parte del metraje y la imagen superior a la parte final de la película. Fuente: www.acheronfilms.net 
En cuanto a composición visual, los espacios de las casas de los dos muestran una evidente simetría (Figura 2). A modo de reflejo, sus casas, como sus vidas, parecen complementarse. La casa de Él es simétrica a la de Ella, como el reflejo en un espejo. Misma cocina, mismo frigorífico rojo, misma mesa y sillas, misma posición del personaje sentado, con la maleta sobre la mesa jugando al mismo juego. Los baños aparecen a través del mismo plano, la misma composición, la misma profundidad de campo, pero con los grifos en lados opuestos. Abundan las composiciones simétricas, sobre todo en los planos en que aparecen los dos personajes protagonistas (los cenitales acostados en la cama, los planos de conjunto del dormitorio con uno a cada lado de la cama, o los primeros planos de los dos sentados en el sofá). Esta simetría en los planos sirve para mostrar complementariedad y equilibrio en la composición y en los personajes, como la primera vez que ambos se besan sentados en el sofá (00:18:31); cuando están en el dormitorio en la cama (00:18:37); cuando ambos están en la cama juntos y los vemos desde el techo (00:32:40). Y otras veces para mostrar por asimetría el distanciamiento o la falta del otro y el desequilibrio de los personajes, por ejemplo cuando Ella está jugando al "ajedrez" contra nadie (00:02:19); cuando Ella está en la cama queriendo hacer el amor y Él se queda dormido por el cansancio del trabajo (00:39:45); cuando Ella se despierta sola en la cama y Él no ocupa su espacio porque se ha ido a trabajar (00:40:02) o cuando Ella está acostada en la cama junto al espacio vacío que ya no ocupa Él (00:50:26). 

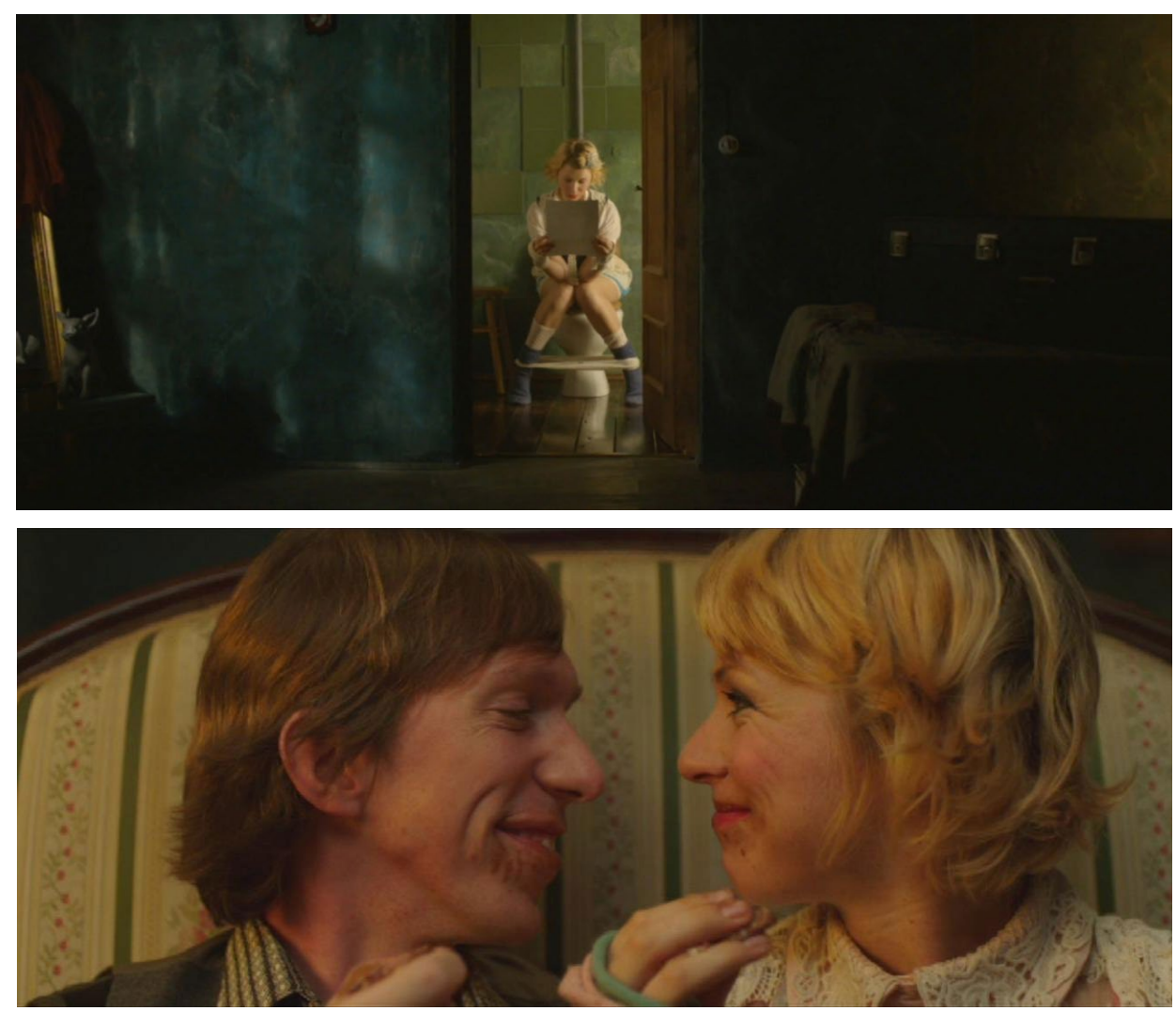

Figura 2. Muestras de la simetría compositiva. En la imagen superior se trabaja con un único personaje que sirve de centro de atención y en la imagen inferior se juega con los dos personajes principales colocados a ambos lados del centro de la composición. Fuente: 
Destaca la centralidad en la composición, con primeros planos frontales muy cercanos con lentes angulares que ofrecen deformaciones en la imagen; por ejemplo, cuando Ella recibe a la madre de Él (00:28:51) y vemos a ambas de la misma forma. Los movimientos de cámara también son muy significativos: son rápidos, sobre todo los travelling de acercamiento y alejamiento de la parte inicial cuando cruzan cartas entre ellos. Uno de los más frecuentes es el travelling lateral de la puerta de la calle a la cocina o hasta la pared opuesta a velocidad lenta para mostrar la evolución de su relación.

Estas ideas están muy marcadas en cuanto a la planificación: abundan los planos medios y cortos por la propia configuración del espacio interior y acotado que presenta el filme. La composición de los planos enfatiza la idea de espacios cerrados, limitados por las paredes y enmarcados por las puertas y los marcos de los espejos.

El fuera de campo es otro elemento importante para reflejar la situación de los personajes. Fuera de campo está el exterior, el cartero, los vecinos, el niño en muchas ocasiones. El espectador se queda con Ella, fundamentalmente, en campo, con su expresión y sus reacciones frente a los sucesos: cuando Ilaman a la puerta, cuando pelean los vecinos, cuando Él se va al trabajo o cuando Ella baña al niño (00:45:50). El parto también queda fuera de campo (00:42:26); y cuando Ella le empieza a dar el pecho al niño este también queda fuera de campo (00:43:35), igual que cuando Ilora desesperadamente en su maleta (00:44:30).

\section{Elementos narrativos}

El foco, es decir, el ángulo de visión desde el que está contada la historia, ofrece la realidad desde la posición de la protagonista femenina, la que más sufre la presión que supone la llegada del hijo. La protagonista se convierte en 
esposa ideal y es el arquetipo de la unión en el lecho nupcial, pero no destaca como madre. Está disgustada con su hijo y descarga sobre él la venganza y el rencor hasta "expulsarlo" de su vida.

En coherencia con esa visión interna, la imagen que nos ofrece el filme se basa en el uso de lentes que crean ligeras distorsiones, con planos singulares, de planos cenitales a contrapicados, movimientos de cámara, aceleraciones en el montaje. Los movimientos de los actores que se acercan a la cámara en primerísimo primer plano consiguen un efecto muy impactante. Ella lo hace en varias ocasiones y su madre en los flashbacks.

Respecto al tratamiento del espacio, la historia se desarrolla fundamentalmente en un único espacio: el piso de Ella, que se convierte en la casa de ambos. Es pequeño, con tres zonas distintas: el dormitorio como espacio de unión entre los personajes, afectiva y sexual; el salón-cocina como espacio de comunicación y diversión, mediada por la máquina de escribir; y el baño, como refugio de los protagonistas. Las tres estancias evolucionan con los personajes a partir del embarazo, sobre todo desde el nacimiento del niño: el dormitorio, por ejemplo, pasa de espacio de unión afectiva y sexual a espacio de distanciamiento y soledad. El salón-cocina cambia de espacio de comunicación y diversión a espacio de incomunicación y de tensiones. El baño pasa de ser un espacio de relax (00:03:05) a un espacio de tensión donde se produce el parto (00:42:26), Ella lucha con el bebé (00:45:58) y conversa consigo misma en el espejo para tomar la decisión más dramática.

El espacio interior es siempre más seguro para el personaje de Ella. El exterior es sinónimo de peligro, fundamentalmente porque nunca ha salido desde que llegó a este "país" cuando era muy pequeña. Del exterior vienen los extraños que Ilaman a la puerta (Asuntos Sociales), de la calle viene el ruido de los vecinos, allí está el trabajo que a Él lo aparta de ella. El exterior vuelve a ser 
una amenaza cuando Ilaman a la puerta mientras ella juega al ajedrez con el niño (00:59:40).

La puesta en escena de estos espacios está muy cuidada; está cargada de detalles que caracterizan al personaje femenino, con tonos pastel y mezclas de colores cálidos o fríos según los estados de ánimo de los personajes, como ya se ha comentado, siempre con una especial atención a las luces puntuales y texturizadas. Objetos antiguos como la radio, la propia máquina de escribir, los muebles, o cualquier elemento de la cocina aportan un aire retro e intemporal a la historia.

El paso del tiempo está representado en la película a base de elipsis temporales normalmente sobre una misma composición, sin variar la posición de la cámara; esto ocurre en la primera cita cuando Ella se cambia de ropa (00:14:04); cuando bailan los dos personajes (00:14:19); cuando Ella decide qué quiere que cocine Él (00:15:56); cuando se desnudan para acostarse (00:18:40); o con aceleraciones del montaje a cámara rápida cuando Él cocina para Ella (00:17:39).

\section{Fase II: Reconocimiento de mitemas (nivel de significación secundaria)}

En esta película, de apariencia cercana a los cuentos de hadas hay varios mitologemas actualizados. Por ejemplo, el Ilamado Síndrome de Peter Pan, por el que un individuo se niega a crecer; o el mitologema basado en el desprecio de la figura paterna/materna hacia el hijo/a. Este aspecto destructor ha sido ocultado en numerosas culturas, sobre todo en las sociedades patriarcales. Sin embargo, es un tema muy recurrente en diversos relatos míticos, poniendo de manifiesto que la madre es capaz de dar la vida a sus hijos, pero también de quitársela. Este tema se plasma en figuras de dioses como Cronos (Saturno), que contrae matrimonio con su hermana Rea y a partir de ese momento siente temor de que sus propios hijos intenten derrocarlo. Otro ejemplo es la diosa 
Hera que a partir del casamiento comienza una relación tormentosa con su esposo Zeus que dará lugar a los hechos más extraños y la venganza de los dos enamorados. Hefesto es el dios del fuego, hijo de Hera; cuando esta ve lo feo que es el hijo que ha parido, lo arroja del Olimpo y el niño queda lisiado -cojo- tras la caída (Cardona, 1996).

También destaca Medea; es el arquetipo de mujer independiente y hechicera. Contrae matrimonio con Jasón, pero decide abandonarla para contraer matrimonio con una joven princesa. Los celos y el deseo de venganza de Medea son tan fuertes que ella decide matar a los hijos que Jasón y ella habían tenido en común.

Por último, Tántalo, hijo de Zeus y de la diosa Hades quiere hacer ver a los dioses lo poderoso que es y les invita a un banquete que organiza en el monte Sípilo. Cuando la comida empieza a escasear, para demostrar su omnipotencia, decide ofrecer a su único hijo Pélope, al cual descuartiza y reparte a los invitados.

Como también lo hicieran cuentos de hadas como Blancanieves (Jiménez, 2016) de los hermanos Grimm, donde la madrastra quiere matar a su hija por celos, en el caso de The Extraordinary Tale of the Times Table la chica representa la actualización de la invariante común a todas estas historias: la mujer que desprecia a su hijo, en este caso porque afecta a su calidad de vida. Como Medea, Ella se siente celosa porque ya no puede disfrutar de Jasón -Él. Aunque los celos de Medea vienen motivados por otra relación amorosa, el tema de fondo es el mismo: una maternidad frustrada que acaba con la vida de uno o varios descendientes. En la película, el hijo de la relación de Ella con Él viene a desestabilizar el equilibrio de la pareja, les obliga a llevar a cabo acciones que se entrometen en su felicidad, como el hecho de que Él tenga que trabajar para mantener a la familia, que eso mismo les obligue a estar separados casi 
todo el día, que no les permita tener tiempo de ocio como pareja o que no puedan mantener relaciones sexuales porque Él está muy cansado de trabajar (00:47:10). Como Hera, Ella también se deshace de su hijo, ya no por ser feo, sino porque si consigue eliminarlo podrá recuperar su vida anterior.

Karyl McBride (2009) expone algunos indicios que permiten identificar a este tipo de madres: sí muestran celos de sus hijos; son incapaces de empatizar con ellos; no pueden afrontar sus propios sentimientos; critican y enjuician a sus descendientes; no los tratan como a tales. Estas madres normalmente manipulan para que se crea que el hijo es el diabólico y la madre la víctima, tal y como ocurre con el personaje de Ella en The Extraordinary Tale of the Times Table.

\section{Fase III: Identificación de los valores simbólicos (análisis iconológico)}

En esta fase final se detectan varios bloques de sentido simbólico. La película hace una reflexión crítica sobre los convencionalismos de la edad adulta: matrimonio, relaciones sexuales, trabajo, maternidad/paternidad. Resulta muy interesante ver cómo, con una puesta en escena propia de los cuentos de hadas, pueda acercarse tanto a los temas que preocupan a la población en edad adulta en el siglo XXI. La protagonista, como otras madres de mitos y cuentos de hadas, desea matar a su hijo, aunque no necesariamente se trate de una muerte literal. Los protagonistas de esta historia representan a una pareja contemporánea que ve su equilibrio roto por la llegada de un hijo inesperado. En esta película se puede ver a cualquier pareja contemporánea con problemas de trabajo, rutinas, responsabilidades, tiempo, ya que las coordenadas espacio temporales no están definidas.

La relación madre/hijo y sus consecuencias sobre la relación madre/padre constituye el principal bloque de sentido profundo. Después del primer 
encuentro sexual entre los protagonistas Ella empieza a dar muestras de embarazo: falta de apetito, náuseas y desmayos. Es entonces cuando se anticipa la tragedia: despierta en la cama y parece estar ya en avanzado estado de gestación (00:25:16), lo cual supone un duro golpe para Ella. Este plano recuerda claramente el comienzo de La metamorfosis de Kafka (2003):

Una mañana, tras un sueño intranquilo, Gregorio Samsa se despertó convertido en un monstruoso insecto. Estaba echado de espaldas sobre un duro caparazón y, al alzar la cabeza, vio su vientre convexo y oscuro, surcado por curvadas callosidades, sobre el que casi no se aguantaba la colcha, que estaba a punto de escurrirse hasta el suelo. (p. 1)

Ella, igual que Gregor no se reconoce, se siente un ser extraño y acto seguido va a la cocina, donde la vemos de espaldas haciendo un gesto con el que parece "acuchillar" su propia barriga (00:25:22) para comprobar después que está agujereando un melón que tiene en las manos. Es una forma gráfica de representar lo que luego declara en uno de los diálogos donde describe su estado de embarazada como "llevar un ser que no siento como mío" (00:31:15). Esta frase ejemplifica perfectamente el sentir de muchas mujeres, que durante siglos han silenciado sus sentimientos hacia la maternidad, que siempre ha sido tratada desde un punto de vista positivo. Este personaje pone voz a cuestiones que la mujer del siglo XXI empieza a plantearse: ¿Debe una mujer necesariamente ser madre a lo largo de su vida? ¿Debe sentirse bien por ser madre? Las discusiones entre ambos personajes empiezan por culpa del bebé. Ella no piensa ceder espacio para el niño, un espacio que no es solo físico, sino vital y poco a poco se convierte en paradigma de ese lado oscuro de la maternidad que, muy tímidamente, empieza a aflorar en torno al momento en que esta película ve la luz. El director, preguntado por estas cuestiones, ratifica este planteamiento del sentido último del filme.

Asociado al tema del nacimiento del hijo está el tema del trabajo, que se convierte en otro elemento clave en la relación. En sí mismo es un elemento 
de distanciamiento, pero la justificación de Él -el "niño" - suma otro elemento de odio de la madre hacia lo que significa su hijo. Esta situación prolongada en el tiempo la lleva a Ella a vencer sus problemas de comunicación y exponerle a Él "hablando" su tristeza y su situación; apenas se ven, ya no practican el sexo, solían hacerlo todo juntos: comían, escuchaban a los vecinos. Pero Él insiste en que no puede dejar su trabajo por él niño. Su única esperanza para estar juntos son las vacaciones. Ella empieza a soñar con el niño como una amenaza real y huye al baño (00:48:45), su lugar de refugio. Es una estructura cíclica, cada vez que su relación con el niño parece mejorar algo hace que ella colapse: en definitiva, "está quitándoselo todo", como ella misma afirma.

Otro de los grandes bloques de sentido del filme es el problema de las relaciones intergeneracionales, que se expone claramente cuando la madre del protagonista no puede entender su elección de pareja o cuando la madre de la chica no la trata de forma acorde a su edad. Tampoco Ella sabe ahora cómo tratar a su hijo, con el que no empatiza desde el primer minuto. El momento crítico llega cuando el niño rompe el bote con las cenizas de la abuela mientras juega y Ella está a punto de golpearle (01:04:24). En el fondo, Ella teme que su madre difunta se vaya a enfadar y siga "sin hablarle", ya que Ella se culpa de la muerte de su progenitora por haberlo deseado soplando las velas de su cumpleaños (01:04:54). Entonces reconoce que su madre no le enseñó las cosas importantes de la vida, pero ¿qué sabía ella de ser madre? Su madre le gritó por tener su primera regla (01:06:19), le contaba la tabla de multiplicar como cuento antes de dormir... Con Ella y su hijo la historia se repite.

El tercer bloque de sentido está asociado al símbolo de la tecnología como barrera comunicativa entre individuos, uno de los grandes problemas del siglo XXI. Los personajes se escriben cartas antes de conocerse y a partir de ese momento el espectador comprende que un elemento fundamental en la relación de ambos será la máquina de escribir. Desde los créditos, está presente 
como elemento de comunicación de ambos personajes, hasta el punto de que Él reconoce no recordar el sonido de su propia voz. Cuando se conocen en persona, la escena transcurre sin diálogo e incluso la composición del plano muestra a uno a cada lado con la máquina de escribir en el centro al fondo (00:12:28). En los momentos en los que Ella quiere comunicarse con Él, va a por la máquina y la coloca en la mesa entre ambos. De ahí en adelante, la tecnología -la máquina es una metáfora de cualquier aparato que mediatiza hoy en día nuestras vidas, ya sea teléfonos móviles, ordenadores, tablets- será la forma de comunicación entre ambos, prevaleciendo frente a un diálogo cara a cara. Por ello, cuando el niño lanza la máquina de escribir a la bañera (00:55:02) se produce un momento clave para hacer avanzar la historia hacia el desastre. El final -marcado por la "desaparición" del niño- ofrece un mensaje inquietante: también se puede ser feliz sin hijos. La maternidad /paternidad no es condición indispensable para que el ser humano se sienta realizado. Un mensaje provocador para el espectador activo que siempre buscan los directores del filme.

\section{Conclusiones}

A través de la película The Extraordinary Tale of the Times Table se ha podido comprobar cómo un producto audiovisual bebe de los temas ancestrales -la maternidad, los problemas de pareja, la comunicación intergeneracional-para actualizarlos de acuerdo con las preocupaciones de la sociedad del momento en que la película es producida. Refleja, a su vez, las preocupaciones del emisor -la maternidad en el sentido negativo, la falta de comunicación mediada por la tecnología- que son a su vez las de la sociedad en la que se inserta. Un contexto intemporal en este caso será crucial para ofrecer al espectador una cierta distancia para la catarsis: sentir que sus problemas se ven reflejados fielmente en la pantalla a través de los personajes más inverosímiles, en un contexto muy particular, pero con una trama que funciona en el nivel 
más profundo -el simbólico - para que cada receptor se sienta identificado. En definitiva, se tratan temas contemporáneos de una sociedad que sigue siendo patriarcal e intenta reforzar los valores más tradicionales para hacer pensar al espectador que otras opciones son posibles.

\section{Referencias}

Barthes, R. (1999). Mitologías. Madrid: Siglo XXI editores.

Cardona, F. L. (1996). Mitología griega. Barcelona: Edicomunicación.

Cassirer, E. (1998). Filosofía de las formas simbólicas. México: Fondo de Cultura Económica.

Cencillo, L. (1998). Los mitos. Sus mundos y su verdad. Madrid: Biblioteca de autores cristianos.

Duch, L. (2002). Mito, interpretación y cultura. Barcelona: Herder.

Durand, G. (2013). De la mitocrítica al mitoanálisis. Barcelona: Anthropos.

Eliade, M. (1999). Mito y realidad. Barcelona: Kairós.

Ferrater-Mora, J. (1992). Diccionario de filosofía. Barcelona: EdhasaSudamericana.

García-Gual, C. (1989). La mitología. Interpretaciones del pensamiento mítico. Barcelona: Montesinos.

García-Ochoa, S. (2017): Iconología y análisis fílmico. Una relación controvertida. La Trama de la Comunicación, 21 (1), 65-83. Recuperado de http://www.scielo.org.ar/pdf/trama/v21n1/v21n1a04.pdf.

Gombrich, E.H. (1986). Imágenes simbólicas. Estudios sobre el arte del Renacimiento. Madrid: Alianza editorial.

Havelock, E.A. (1996). La musa aprende a escribir: reflexiones sobre la oralidad 
y la escritura desde la Antigüedad hasta el presente. Barcelona: Paidós.

Holland, J. (2013). The Extraordinary Tale: Film Review. En The Hollywood Reporter. Recuperado de http://www.hollywoodreporter.com/review/ extraordinary-tale-film-review-665094.

Huici, A. (1998). El mito clásico en la obra de Jorge Luis Borges. El Laberinto. Sevilla: Alfar.

Jiménez, W. (2016). Madres que odian a sus hijos. En Amor Distorsionado. Recuperado de http://www.amordistorsionado.com/madres-que-odian-asus-hijasos/

Jung, C. (1968). Collected Works of C. G. Jung, Vol. 9, parte 1. Princeton: University Press.

Jung, C.G. y Kerényi, K. (2004). Introducción a la esencia de la mitología. Madrid: Siruela.

Kafka, F. (2003). La metamorfosis. Biblioteca Virtual Universal. Recuperado de http://www.biblioteca.org.ar/.

Kolakowski, L. (1990). La presencia del mito. Madrid: Cátedra.

Lévi-Strauss, C. (1958). Antropología estructural. Buenos Aires: Ed. Universitaria.

Lévi-Strauss, C. (1987). Mito y significado. Madrid: Alianza.

McBride, K. (2009). Will I evere be good enough? Healing de daughters of narcissistic mothers. Nueva York: Atria Paperback.

McLuhan, M. (1985). La galaxia Gutenberg: genesis del "Homo Tipographicus". Barcelona: Planeta.

Müller, M. (2011). Iconography and Iconology as a Visual Method and Approach. En Margolis, E. y Pauwels, L. (Eds.), The SAGE Handbook of Visual Research Methods. Londres: SAGE Publications. 
Panofsky, E. and Heckscher, W. (1997). Three Essays on Style. Cambridge, Massachusetts: The MIT Press.

Panofsky, E. (1987): Iconografía e iconología: introducción al estudio del arte del Renacimiento. En Panofsky, E., El significado de las artes visuales (pp. 45-76). Madrid: Alianza forma.

Rosales, E. (1996). El mito. Sevilla: Cuadernos Arbolays.

Segal, R.A. (2004). Myth. A very short introduction. Estados Unidos: Oxford University Press.

Stefanello, G. (2008). La mediación social a través del uso de mitologemas sobre la Amazonía en la prensa brasileña. Mediaciones Sociales. Revista de Ciencias Sociales y de la Comunicación, 3, 219-239. Recuperado de http:// www.ucm.es/info/mediars.

Van Leeuwen, T. (2001). Semiotics and Iconography. En van Leeuwen, T. y Jewitt, C. (Eds.), Handbook of Visual Analysis (pp. 92-118). Londres: Thousand Oaks.

Warburg, A. (2010). Atlas Mnemosyne. Madrid: Akal.

Zavala, H. (2009). Herramientas del diseño. Enfoco, 17(3), 19-25. Recuperado de http://media.eictv.org/enfoco_digital/ENFOCO17.pdf.

Como citar: Martínez-García, Á. y Gómez-Aguilar, A. (2019). El lado oscuro de la maternidad: actualización de mitos en la película The Extraordinary Tale of the Times Table (2013). Revista KEPES, 16 (20), 15-40. DOI: 10.17151/kepes.2019.17.20.2 